\title{
Impairment of testicular function in adult male Japanese quail (Coturnix japonica) after a single administration of 3-methyl-4-nitrophenol in diesel exhaust particles
}

\author{
ChunMei $\mathrm{Li}^{1,2}$, Shinji Takahashi ${ }^{3}$, Shinji Taneda ${ }^{4}$, Chie Furuta ${ }^{1,2}$, \\ Gen Watanabe ${ }^{1,2}$, Akira K Suzuki ${ }^{4}$ and Kazuyoshi Taya ${ }^{1,2}$ \\ ${ }^{1}$ Department of Basic Veterinary Science, The United Graduate School of Veterinary Sciences, Gifu University, Gifu 501-1193, Japan \\ ${ }^{2}$ Laboratory of Veterinary Physiology, Department of Veterinary Medicine, Faculty of Agriculture, Tokyo University of Agriculture and Technology, \\ Tokyo 183-8509, Japan \\ ${ }^{3}$ Ecological Effect Research Team, Dioxin and Environmental Endocrine Disrupter Research Project, National Institute for Environmental Studies, \\ 16-2 Onogawa, Tsukuba, Ibaraki 305-8506, Japan \\ ${ }^{4}$ Toxicology and Effects Research Team, PM2·5/DEP Research Project, National Institute for Environmental Studies, 16-2 Onogawa, Tsukuba, Ibaraki 305-8506, \\ Japan \\ (Requests for offprints should be addressed to A K Suzuki; Email: suzukiak@nies.go.jp)
}

\begin{abstract}
The effects of 3-methyl-4-nitrophenol (PNMC), a component of diesel exhaust, on reproductive function were investigated in adult male Japanese quail. The quail were treated with a single i.m. dose of PNMC (78, 103 or $135 \mathrm{mg} / \mathrm{kg}$ body weight), and trunk blood and testes were collected 1, 2 or 4 weeks later. Various levels of testicular atrophy were observed in all groups treated with PNMC. Sperm formation, cloacal gland area, and plasma LH and testosterone concentrations were also reduced in birds with testicular atrophy. To determine the acute effect of PNMC on gonadotrophin from the pituitary, adult male quail were administrated a single i.m. injection of PNMC $(25 \mathrm{mg} / \mathrm{kg})$, and plasma concentrations of LH were measured at 1, 3 and $6 \mathrm{~h}$. This dose significantly lowered plasma levels of $\mathrm{LH}$ at all three time points. These results suggest that PNMC acts on the hypothalamus-pituitary axis,
\end{abstract}

by reducing circulating LH within a few hours of administration and subsequently reducing testosterone secretion. In addition, in order to investigate the direct effects of PNMC on the secretion of testosterone from testicular cells in quail testes, cultured interstitial cells containing Leydig cells were exposed to PNMC $\left(10^{-6}, 10^{-5}\right.$ or $\left.10^{-4} \mathrm{M}\right)$ for 4,8 or $24 \mathrm{~h}$. These quantities of PNMC significantly reduced the secretion of testosterone in a time- and dose-dependent manner. The present findings also suggest a direct effect of PNMC on the testis to reduce testosterone secretion. This study clearly indicates that PNMC induces reproductive toxicity at both the central and testicular levels, and disrupts testicular function in adult male quail.

Journal of Endocrinology (2006) 189, 555-564

\section{Introduction}

Diesel air pollution is a significant environmental problem and has broad effects on human health, including lung cancer (McClellan 1987, Ichinose et al. 1997), allergic rhinitis (Muranaka et al. 1986, Takafuji et al. 1987) and bronchial asthma-like disease (Sagai et al. 1993, Miyabara et al. 1998). Diesel exhaust particles (DEP), the soluble organic fraction of particulate matter from diesel exhaust, are also toxic to the male and female reproductive systems (Watanabe \& Oonuki 1999, Yoshida et al. 1999, Tsukue et al. 2001, 2002). However, the specific compounds responsible for this toxicity are still unclear.

We recently isolated four nitrophenol derivatives 4-nitrophenol, 2-methyl-4-nitrophenol, 3-methyl-4nitrophenol (PNMC) and 4-nitro-3-phenylphenol - from
DEP and showed that they had vasodilatory activity (Mori et al. 2003, Taneda et al. 2004a), oestrogenic activity (Furuta et al. 2004, 2005, Taneda et al. 2004b), and anti-androgenic activity (Taneda et al. 2004b). In addition to its presence in DEP, PNMC is a degradation product of the insecticide fenitrothion (Bhushan et al. 2000), a widely used pesticide with high potential for human, livestock and poultry exposure in both rural and residential environments. The accumulation of PNMC from these sources could have significant effects on wildlife and human health via disruptions of endocrine and reproductive systems.

Despite the potentially significant effects, possible biological impacts and basic data on the toxicity of PNMC are still unknown. To determine the basic potential endocrine and reproductive toxicities of PNMC, we used 
the adult male terrestrial Japanese quail (Coturnix japonica). As a laboratory animal, Japanese quail has been extensively used in reproductive toxicity testing. Quail are considered to be representative of terrestrial birds and are accepted models for assessing both the acute and chronic effects of pesticides and other chemicals in wild birds (OECD 1993, EPA 1996), because spermatogenesis is well characterized (Lin \& Jones 1992) and the cloacal gland is a good marker of gonadal development (Ottinger \& Brinkley 1979a). In the present study, we used this animal model to examine the in vivo effects of a single dose of PNMC and the in vitro effects on the testicular function of adult male quail.

\section{Materials and Methods}

\section{Chemicals}

PNMC (4-nitro-m-cresol) was purchased from Tokyo Kasei Kogyo Co. Ltd (Tokyo, Japan). Collagenase (type V), soybean trypsin inhibitor and Medium 199 (M199) were purchased from Sigma.

\section{Birds}

Japanese quail (Coturnix japonica) came from low antibody response (L) selected lines, in which chicks hatch after 17 days of incubation and the birds reach sexual maturity in 6 weeks. Birds were provided with food (Kanematsu quail diet; Kanematsu Agri-tech Co. Ltd, Ibaraki, Japan) and water, and were allowed to feed ad libitum. Male birds (6-9 weeks old) were housed in metal cages in a controlled environment (lights on, 0500-1900 h; temperature, $23 \pm 2{ }^{\circ} \mathrm{C}$; humidity, $50 \pm 10 \%$; air exchanged 20 times hourly). This study was conducted in accordance with the Guiding Principles in the Use of Animals in Toxicology, and was approved by the Animal Care and Use Committee of the Japanese National Institute for Environmental Studies.

\section{Administration of PNMC}

Mature male Japanese quail were treated with a single i.m. injection of PNMC (78, 103 or $135 \mathrm{mg} / \mathrm{kg}$ body weight). The doses were decided by the preliminary experiments on half-maximal lethal dose $\left(\mathrm{LD}_{50}\right)$ of PNMC in the adult male quail. The $\mathrm{LD}_{50}$ of PNMC in the adult male quail was $135 \mathrm{mg} / \mathrm{kg}$, so the three lower doses (including $135 \mathrm{mg} / \mathrm{kg}$ ) were adopted in this study. Controls were injected with vehicle alone (PBS containing 0.05\% Tween $80)$. The quail ( $n=6-9$ per group) were weighed and killed by decapitation at 1,2 and 4 weeks after the injection. Following decapitation, blood samples were collected in heparinized plastic tubes and centrifuged at $1700 \mathrm{~g}$ for $15 \mathrm{~min}$ at $4{ }^{\circ} \mathrm{C}$. Plasma was separated and stored at $-20{ }^{\circ} \mathrm{C}$ until it was assayed for testosterone and luteinizing hormone $(\mathrm{LH})$. The testes were collected and weighed, and the cloacal gland area (longest length $\times$ greatest width) was measured.

\section{Regrouping according to testicular atrophy}

Birds with testicular atrophy were found in all PNMCtreated groups, but none was found in the control groups. Birds were separated into three atrophy groups (severe, intermediate and mild) on the basis of testicular weight. The severe atrophy group included birds in which the weight of both testes was at least $50 \%(1.33 \pm 0.064 \mathrm{~g})$ lighter than the mean of the control group $(2 \cdot 66 \pm$ $0 \cdot 128 \mathrm{~g}$ ). The intermediate group included birds with one testis weighing less than $50 \%$ of the control weight. The criterion for the mild atrophy group was one testis weight of $50-70 \%$ of the control weight.

\section{Histopathology}

After weighing, the testes were immediately fixed in $4 \%$ paraformaldehyde (Wako Japan Co, Osaka, Japan) in $0.05 \mathrm{M}$ PBS ( $\mathrm{pH} 7 \cdot 4$ ), and embedded in paraffin. The paraffin-embedded testes were serially sectioned at $6 \mu \mathrm{m}$ and placed on poly-L-lysine-coated slides (Sigma) for haematoxylin and eosin staining, and examined by light microscopy for histology.

\section{Effects of PNMC on hypothalamus-pituitary function}

To observe the direct effects of PNMC on the secretion of $\mathrm{LH}$, birds were treated with a single i.m. injection of a small amount of PNMC $(25 \mathrm{mg} / \mathrm{kg})$ to avoid the acute toxic effect that was observed at the highest dose setting (see Results). Control birds were treated with vehicle alone (PBS containing 0.05\% Tween 80). Eight birds were used in both groups. Blood was collected in heparinized syringes from the jugular vein 1 and $3 \mathrm{~h}$ after the injection. Six hours after the injection, birds were killed by decapitation and blood was collected. All blood samples were centrifuged at $1700 \mathrm{~g}$ for $15 \mathrm{~min}$ at $4{ }^{\circ} \mathrm{C}$, and plasma was separated and stored at $-20{ }^{\circ} \mathrm{C}$ until it was assayed for $\mathrm{LH}$.

\section{Interstitial cell preparation}

Interstitial cell preparations containing Leydig cells were prepared from the testes of adult quail as described previously (Klinefelter et al. 1987) with minor modifications. Adult quail were killed by cervical dislocation and the testes immediately removed. Testicular cells were dispersed by treating the decapsulated testis in M199 with $0.71 \mathrm{mg} / \mathrm{ml}$ sodium bicarbonate and $2.21 \mathrm{mg} / \mathrm{ml}$ HEPES containing collagenase $(0 \cdot 25 \mathrm{mg} / \mathrm{ml})$ and soybean trypsin inhibitor $(0.025 \mathrm{mg} / \mathrm{ml})$ at $37^{\circ} \mathrm{C}$ for $30 \mathrm{~min}$ in a shaking water bath. After incubation, the supernatant, containing Leydig cells, was decanted through nylon mesh to 
Table 1 Testicular atrophy in adult male quail treated with PNMC after 1, 2 and 4 weeks

\begin{tabular}{|c|c|c|c|c|c|c|c|}
\hline & \multirow{2}{*}{$\begin{array}{l}\text { Dose } \\
(\mathrm{mg} / \mathrm{kg})\end{array}$} & \multirow{2}{*}{$\begin{array}{l}\text { Number } \\
\text { of } \\
\text { birds }\end{array}$} & \multirow{2}{*}{$\begin{array}{l}\text { Number } \\
\text { of } \\
\text { deaths }\end{array}$} & \multicolumn{3}{|c|}{ Grade of atrophy } & \multirow{2}{*}{$\begin{array}{l}\text { Rate of } \\
\text { atrophy } \\
(\%)\end{array}$} \\
\hline & & & & Severe & Intermediate & Mild & \\
\hline \multicolumn{8}{|l|}{ Group } \\
\hline \multirow[t]{4}{*}{1 week } & 0 & 7 & 0 & 0 & 0 & 0 & 0 \\
\hline & 78 & 8 & 0 & 0 & 1 & 1 & 25 \\
\hline & 103 & 8 & 0 & 0 & 0 & 2 & 25 \\
\hline & 135 & 9 & 3 & 0 & 0 & 1 & 17 \\
\hline \multirow[t]{4}{*}{2 weeks } & 0 & 8 & 0 & 0 & 0 & 0 & 0 \\
\hline & 78 & 10 & 0 & 3 & 2 & 2 & 70 \\
\hline & 103 & 10 & 1 & 2 & 1 & 3 & 67 \\
\hline & 135 & 10 & 1 & 1 & 0 & 2 & 33 \\
\hline \multirow[t]{4}{*}{4 weeks } & 0 & 7 & 0 & 0 & 0 & 0 & 0 \\
\hline & 78 & 8 & 0 & 0 & 1 & 2 & 38 \\
\hline & 103 & 8 & 0 & 0 & 1 & 2 & 38 \\
\hline & 135 & 9 & 2 & 0 & 0 & 1 & 14 \\
\hline
\end{tabular}

remove debris. The cells were washed by centrifugation and resuspended in $10 \mathrm{ml}$ M199 with $1 \%$ fetal bovine serum. The viability of the cells was evaluated by means of the trypan blue exclusion test and was found to be $92 \%$. Cells $\left(10^{5}\right.$ cells/well per $100 \mu$ l) were cultured in $96-$ well culture plates at $37^{\circ} \mathrm{C}$ under a $95 \%$ air $-5 \% \mathrm{CO}_{2}$ atmosphere. Following a $20 \mathrm{~min}$ equilibration period, cells were exposed for 4,8 or $24 \mathrm{~h}$ to $10^{-6}, 10^{-5}$ or $10^{-4} \mathrm{M}$ PNMC $(100 \mu \mathrm{l})$ dissolved in M199. The viability of treated cells was determined by a lactate dehydrogenase (LDH) Cytotoxicity Detection Kit (code number MK401; Takara, Japan). No significant differences in LDH release activity were observed between cells treated with PNMC and control cells (data not shown). Conditioned media were assayed for testosterone.

\section{Determination of LH and testosterone concentrations in plasma, and of testosterone concentrations in conditioned media}

Plasma concentrations of LH and testosterone, and testosterone concentrations in conditioned media, were determined by specific RIAs. LH concentrations were measured with a USDA-ARS RIA kit (Beltsville, MD, USA) for chicken LH. The antiserum used was antiavian LH (HAC-CH27-01 RBP75). The hormone for iodination was chicken USDA-cLH-I-3. The results are expressed in terms of USDA-cLH-K-3. The intra- and inter-assay coefficients of variation were $5 \cdot 2$ and $11 \cdot 2 \%$ respectively. USDA-cLH-I-3 and USDA-cLH-K-3 were kindly provided by Dr John A Proudman, Biotechnology and Germplasm Laboratory, Animal and Natural Resources Institute, Beltsville, MD, USA (Krishnan et al. 1994). The antiserum against avian LH was kindly provided by the Biosignal Research Center, Institute for Molecular and Cellular Regulation, Gunma, Japan (Hattori \& Wakabayashi 1979).

Plasma concentrations of testosterone were determined by a double-antibody RIA system with ${ }^{125}$ I-labelled radioligands as described previously (Taya et al. 1985). The antiserum against testosterone (GDN 250) (Gay \& Kerlan 1978) was kindly provided by Dr G D Niswender, Colorado State University (Fort Collins, CO, USA). The intra- and inter-assay coefficients of variation were 6.3 and $7 \cdot 2 \%$ respectively.

\section{Statistical analysis}

All data are expressed as means \pm S.E.M. Statistical analysis was performed using one-way ANOVA followed by Dunnett's test. The acute effects of PNMC on the secretion of LH challenges were analyzed using two-way ANOVA followed by Dunnett's test. Statistical analysis was performed using the software program StatView 5.0 (SAS Institute Inc, USA). A probability value of $P<0 \cdot 05$ was considered significant.

\section{Results}

Acute effect of PNMC

Of 28 birds treated with the highest dose of PNMC $(135 \mathrm{mg} / \mathrm{kg}), 6$ died within $10 \mathrm{~min}$ of treatment (Table 1). Of 26 birds in the $103 \mathrm{mg} / \mathrm{kg}$ treatment group, one bird died. The birds showed behaviour such as dyspnoea, opening the beak and tremor prior to death. No birds died in the $78 \mathrm{mg} / \mathrm{kg}$ or control groups. The surviving birds in all treatment groups grew normally, with no differences in body weights (data not shown).

\section{Testicular atrophy}

Results for testicular atrophy are shown in Tables 1 and 2. The morphology and histology of atrophic testes are shown in Fig. 1. PNMC treatment induced testicular atrophy as early as 1 week after treatment, but neither the 

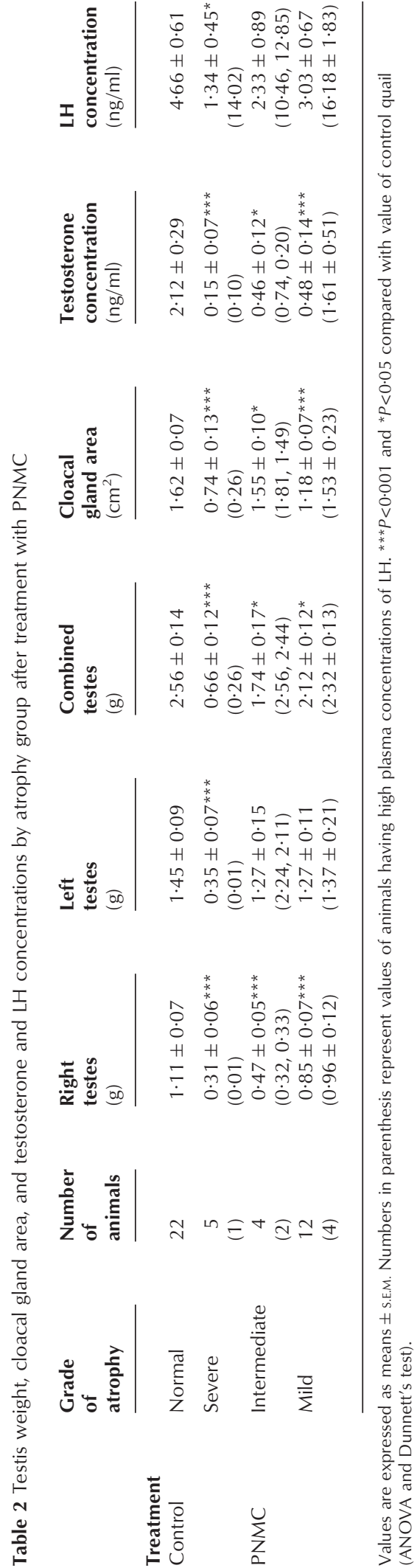

severity nor the incidence of atrophy showed a dosedependent relationship (Table 1). The highest rate of testicular atrophy was observed 2 weeks after treatment with PNMC in all groups. In birds receiving 78 and $103 \mathrm{mg} / \mathrm{kg}$ PNMC, 70 and $67 \%$ of birds showed testicular atrophy respectively (Table 1 ). Some birds showed significant weight decreases in both testes, but others showed an asymmetrical decrease (Table 2). In most cases, the right testis was significantly decreased in size, whereas the left testis was not significantly different from the controls (Table 2).

\section{Morphology and histology of the testes and cloacal glands}

Overall testicular morphology was normal in the control group (Fig. 1A), whereas PNMC treatment induced severe atrophy, either bilaterally or on the right side only (Fig. 1B and C). Control sections showed compartmentalization of germ cells in the seminiferous tubules, with spermatozoa visible in normal-sized lumen (Fig. 1D). In birds with testicular atrophy on one side, seminiferous tubules contained only a thin layer of spermatogenic lineage cells, and spermatids and spermatozoa were absent (Fig. 1E). In contrast, paired atrophic testes showed no compartmentalization of germ cells or spermatozoa, and had highly atrophic seminiferous tubules that were devoid of all cells except spermatogonia and Sertoli cells (Fig. 1F). Control cloacal glands had normal morphology and produced cloacal gland foam (Fig. 1G), whereas PNMCtreated birds with testicular atrophy had smaller cloacal glands and did not produce cloacal foam (Fig. 1H and I).

\section{Plasma concentrations of $\mathrm{LH}$ and testosterone}

Plasma concentrations of $\mathrm{LH}$ and testosterone in PNMCtreated birds are shown in Figs 2 and 3. There were no treatment-induced changes in basal levels of plasma LH at any time point, with relatively large individual variation (Fig. 2). Plasma concentrations of testosterone were significantly lower in both the 78 and $103 \mathrm{mg} / \mathrm{kg}$-treated groups at 1,2 and 4 weeks after PNMC treatment (Fig. 3A and B), whereas the high-dose group showed a significant decrease only at 4 weeks after treatment (Fig. 3C).

Plasma concentrations of $\mathrm{LH}$ and testosterone in birds grouped by atrophy level are shown in Table 2 . There are two types of circulating levels of LH in PNMC-treated birds having various grades of atrophy of the testes. The first type of bird revealed that plasma concentrations of LH were significantly lower in the severe atrophy group $(1.34 \pm 0.45 \mathrm{ng} / \mathrm{ml})$ as compared with controls $(4.66 \pm$ $0.61 \mathrm{ng} / \mathrm{ml}$ ) (Table 2). Plasma concentrations of LH in this type of bird decreased with increasing severity of testicular atrophy, and the level correlated with testis weight. In this type of bird, plasma concentrations of testosterone were significantly lower in severe, intermediate and mild 

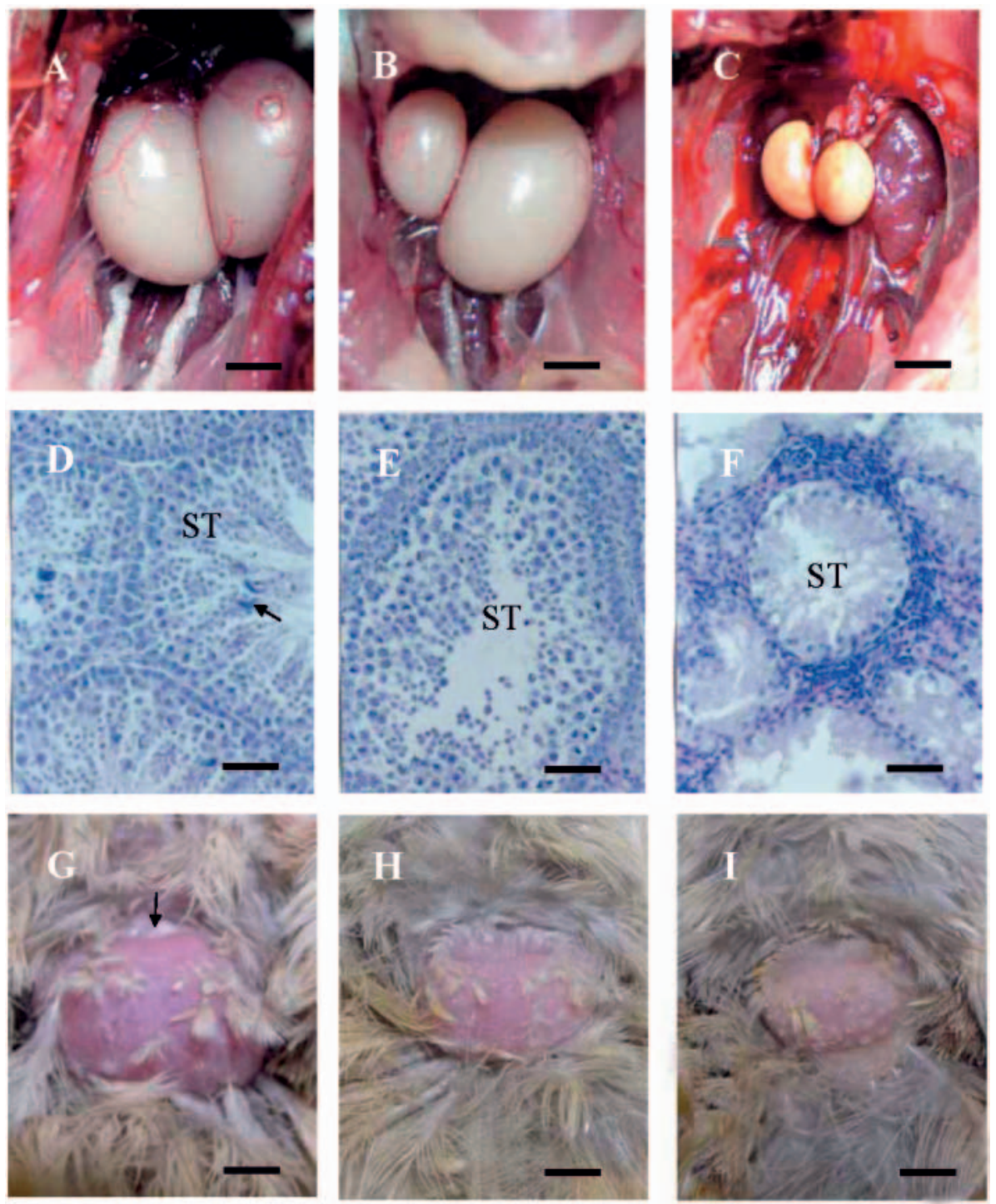

Figure 1 Representative testicular and cloacal gland morphology and histology. (A) The testes of vehicle-treated (control) quail showed normal overall morphology. The testes of PNMC-treated quail showed asymmetrical (B) or bilateral (C) atrophy. (D) The testes of vehicle-treated (control) quail showed different stages of spermatogenesis and compartmentalization of germ cells in the seminiferous tubules. (E) The spermatogenic lineage showed losses of spermatids and spermatozoa in the asymmetrically atrophic testes. (F) Elimination of germ cells and the presence of only spermatogonia and Sertoli cells in bilaterally atrophic testes. (G) The cloacal gland of vehicle-treated (control) quail showed normal morphology and produced cloacal gland foam. The size of the cloacal gland was reduced and no cloacal gland foam appeared in quail with asymmetric testes $(\mathrm{H})$ or bilaterally atrophic testes (I). ST, seminiferous tubules; arrows indicate sperm (D) and cloacal gland foam (G). Haematoxylin and eosin stains. Scale bars represent: A-C=6 mm; D-F=50 $\mu \mathrm{m} ; \mathrm{G}-\mathrm{I}=4 \mathrm{~mm}$.

atrophy groups as compared with controls. It is also correlated with testis weight (Table 2). On the other hand, the second type of bird showed plasma concentrations of LH that were higher compared with controls although they had atrophic testes and low levels of testosterone. This type of bird was observed in 1 out of 6,2 out of 6 , and 4 out of 16 of the birds in the severe, intermediate and mild atrophy groups respectively. Data are shown in parentheses in each group (Table 2).

\section{Cloacal gland area}

Cloacal gland area was significantly decreased in all atrophy groups, with the lowest value observed in the 

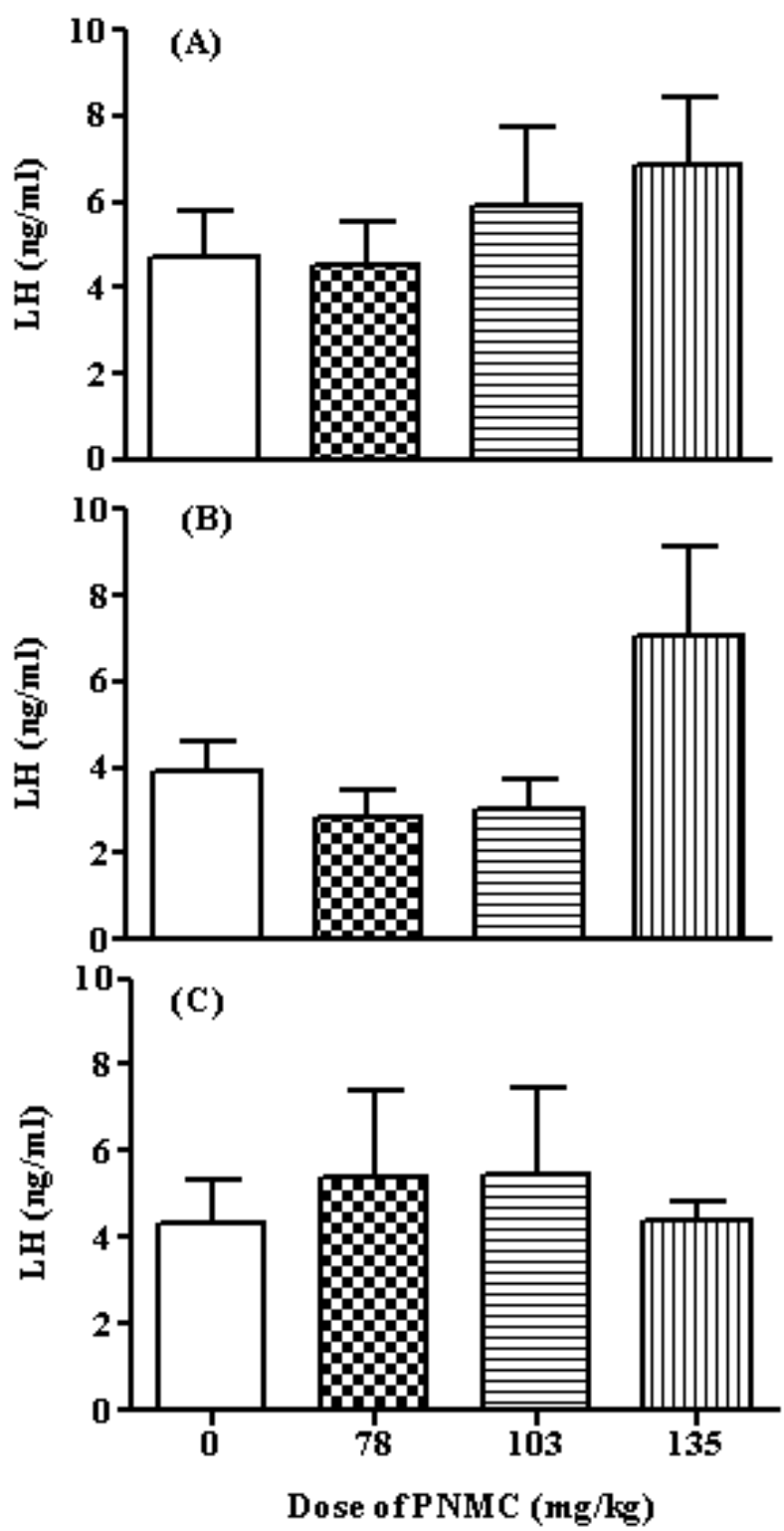

Figure 2 Plasma concentrations of $\mathrm{LH}$ in adult male quail treated with PNMC (78, 103 and $135 \mathrm{mg} / \mathrm{kg}$ ) after 1 week (A), 2 weeks (B) or 4 weeks (C). Each bar represents the mean \pm S.E.M. of six to nine quails per group.

severe atrophy group. Changes in cloacal gland area were similar to plasma levels of testosterone (Table 2).

\section{Acute effects of PNMC on secretion of $\mathrm{LH}$}

There was a clear time-dependent decline in plasma $\mathrm{LH}$ concentrations in the group treated with PNMC (Fig. 4). PNMC treatment $(25 \mathrm{mg} / \mathrm{kg})$ significantly reduced plasma LH concentrations $(P<0 \cdot 05)$ from $1 \mathrm{~h}$ after injection.
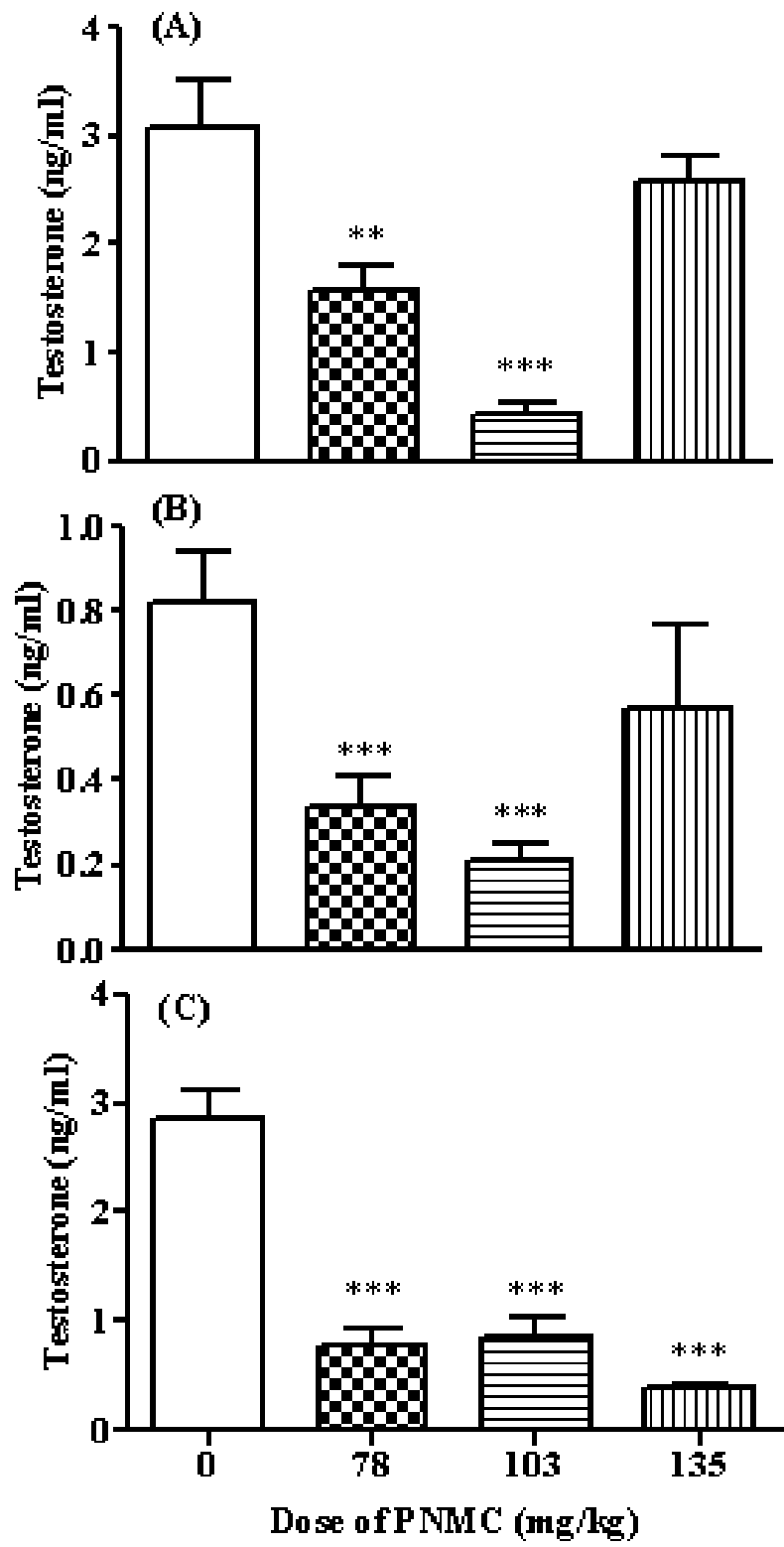

Figure 3 Plasma concentrations of testosterone in adult male quail treated with PNMC $(78,103$ or $135 \mathrm{mg} / \mathrm{kg})$ after 1 week $(\mathrm{A})$,

2 weeks (B) or 4 weeks (C). Each bar represents the mean \pm s.E.M. of six to nine quails per group. ${ }^{* *} P<0 \cdot 001$ and ${ }^{* *} P<0 \cdot 01$ compared with control quail (Dunnett's test).

Dose- and time-dependent effects of PNMC on testosterone secretion of interstitial cells

The dose- and time-dependent effects of PNMC on testosterone secretion into interstitial cell cultured medium were examined (Fig. 5). In the cells exposed to PNMC for $4 \mathrm{~h}$, the amount of testosterone secretion was almost the same as in the control groups. However, a significant 


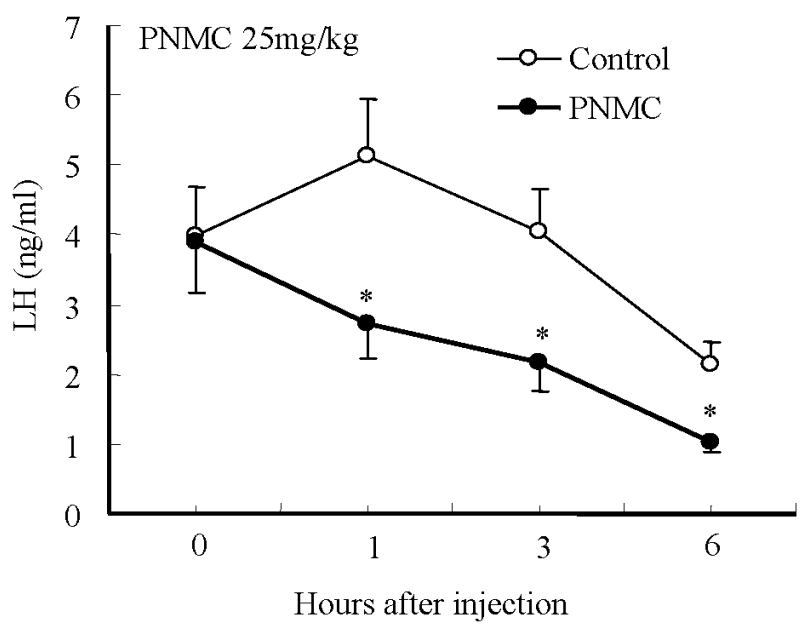

Figure 4 Changes in plasma concentrations of $\mathrm{LH}$ in adult male quail treated with vehicle (control; O) or PNMC $(25 \mathrm{mg} / \mathrm{kg}$; $)$ ). Each bar represents the mean \pm S.E.M. of eight quails per group. ${ }^{*} P<0 \cdot 05$ compared with control when analyzed using two-way ANOVA followed by Dunnett's test.

reduction in testosterone secretion was detected in cells treated with $10^{-6}, 10^{-5}$ or $10^{-4} \mathrm{M}$ PNMC for $8 \mathrm{~h}$, and in cells treated with $10^{-6}$ and $10^{-5} \mathrm{M}$ PNMC for $24 \mathrm{~h}$.

\section{Discussion}

To our knowledge, this is the first report demonstrating that a specific component of DEP induced testicular impairment in an avian model. A single administration of PNMC in adult male Japanese quail induced acute toxicological responses as well as significant testicular

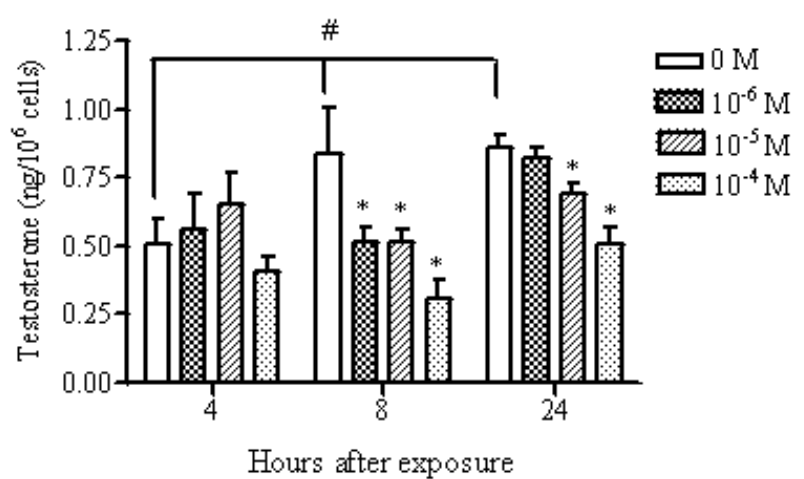

Figure 5 Dose- and time-dependent effect of PNMC on secretion of testosterone in quail testicular interstitial cell culture. The cells were incubated for 4,8 or 24 h in M199 containing different doses of PNMC $\left(10^{-6}, 10^{-5}\right.$ or $\left.10^{-4} \mathrm{M}\right)$. Each bar represents the mean \pm S.E.M. $(n=6) .{ }^{*} P<0 \cdot 05$ compared with the same time control; ${ }^{\#} P<0 \cdot 05$ compared with the 4 -h control (Dunnett's test). atrophy and decreases in plasma concentrations of $\mathrm{LH}$ and testosterone.

The acute toxicological responses were observed from the birds treated with the high dose $(135 \mathrm{mg} / \mathrm{kg})$, and the conditions encountered were dyspnoea and tremor prior to death. From these conditions it can be speculated that PNMC causes acute toxicity and death, possibly by a blood pressure drop followed by an ischaemic shock, as it has been reported that PNMC has a potent vasodilating activity (Mori et al. 2003, Taneda et al. 2004a).

The present study clearly demonstrated that there are two types of responses in secretion of $\mathrm{LH}$ and testosterone in PNMC-treated birds. In the first type, PNMC-treated birds showed low plasma levels of both LH and testosterone. On the other hand, the second type of bird treated with PNMC showed high levels of LH but low levels of testosterone. These results clearly indicate the site of action of PNMC in male quail. The first type of response suggests a direct effect of PNMC on the hypothalamus and pituitary axis to reduce secretion of LH. In this case, therefore, it is suggested that PNMC firstly act on the hypothalamus to reduce pulsatile secretion of gonadotrophin-releasing hormone $(\mathrm{GnRH})$ from the hypothalamus, and then reduces pulsatile secretion of $\mathrm{LH}$ from anterior pituitary glands, followed by a reduction of testosterone secretion from the testis. In addition, in the present study, we demonstrated that plasma concentrations of LH were significantly decreased from $1 \mathrm{~h}$ after a single injection of PNMC. These results strongly support the supposition that PNMC may act directly on the hypothalamus-pituitary axis to reduce $\mathrm{GnRH}$ release from the hypothalamus, and subsequently reduce $\mathrm{LH}$ release from the anterior pituitary gland. On the other hand, the second type of response suggests a direct effect of PNMC on the testis to reduce secretion of testosterone. In this case, it is suggested that PNMC firstly acts directly on the testes to reduce testosterone secretion. This reduction of testosterone induces hypersecretion of $\mathrm{GnRH}$ from the hypothalamus and subsequently increased secretion of LH from anterior pituitary glands. It is well known that Leydig cells play a crucial role in synthesizing testosterone and regulating the process of spermatogenesis (Senger 1999). Alteration of Leydig cell function can lead to adverse effects on testicular functions (Senger 1999). In the present study, we have demonstrated that PNMC reduces testosterone production in cultured testicular interstitial cells. This observation is in agreement with in vivo studies of the second type of bird that showed higher LH levels and lower testosterone levels, in which the testosterone levels were suppressed prior to the toxic effects to the pituitary that would reduce the LH levels. The present results, therefore, strongly suggest that PNMC has a direct effect on the testis, in addition to the hypothalamus and the pituitary; however, an exact explanation of these two different types of response is not possible at the present time. 
Testicular atrophy often showed an asymmetric response, with atrophy most frequently observed in the right testis. A characteristic feature of sexual development in both female and male birds is gonadal asymmetry: the right ovary does not develop, and the right testis is often slightly smaller than the left (Lillie 1952). Treatment of avian embryos with an oestrogenic chemical, diethylstilboestrol, induces a similar asymmetrical pattern, with greater atrophy in the right testis (Rissman et al. 1984, Perrin et al. 1995). In birds, the left embryonic gonad has ambisexual potential, whereas the right gonad is exclusively masculine (Perrin et al. 1995). The mechanism underlying this phenomenon requires further study.

The atrophic paired testes showed no compartmentalization of germ cells and spermatozoa, and seminiferous tubules were atrophic and almost devoid of cells except for the spermatogonia and Sertoli cells. These results suggest that circulating gonadal hormones in the treated birds were reduced with the addition of the toxic effects of PNMC to the seminiferous tubules. The direct effect of PNMC on testes results in a decrease in spermatogenesis, leading to a reduction in the sperm production of treated birds. In avian testes, interstitial cells (Leydig cells), as well as testicular germ cells and Sertoli cells, contain steroidogenic enzymes, which produce progesterone, androgen and oestrogen (Purohit et al. 1977, Kwan et al. 1995, Rosenstrauch et al. 1998). Thus, steroidogenic activities were destroyed in the treated-group testes because the seminiferous epithelium was thinner and thus decreased the sperm population.

The present study showed that the cloacal gland area in birds with testicular atrophy was significantly smaller than that in normal birds. The androgen-dependent cloacal gland, posterior to the cloaca, is a secondary sex characteristic unique to the genus Coturnix. The cloacal gland contains androgen receptors and grows in response to circulating androgen (Ottinger \& Brinkley 1979a, 1979b, Balthazart et al. 1984, Kaku et al. 1993), so it is a widely used indicator of androgen status in the male during sexual maturation. The decrease in cloacal gland area in the treated groups may be attributed to the reduced testosterone level recorded in the present study.

We have reported earlier that PNMC isolated nitrophenol derivative compound from DEP has been shown to posses oestrogenic activity in vivo and in vitro (Taneda et al. 2004b, Furuta et al. 2004, 2005). A previous paper reported that an oestrogenic chemical bisphenol-A reduced the weight of the combs and testes in the male chicken (Furuya et al. 2003). It is well known that the growth of the comb and testes are highly promoted by testosterone and inhibited by oestrogen (Balthazart \& Hendrick 1978). In addition, PNMC also has antiandrogenic activity in vitro (Taneda et al. 2004b). Previous reports have shown that flutamide, a potent androgen antagonist, decreased accessory sex organ weight in rats in vivo (Yamada et al. 2000, Ashby et al. 2004). It is suggested that the oestrogenic and anti-androgenic potency of PNMC may be involved in the suppression of testicular function in the PNMC-treated quail in the present study. In the present study, the effect of PNMC on the secretion of testosterone is not dose dependent. However, the present results suggest that the ratio of oestrogenic and anti-androgenic potency of PNMC may be involved in this phenomenon.

The present study is also important from an environmental perspective. A remarkable amount of DEP are discharged into the air of many countries. In Japan 58902 tons (Japan Environmental Agency 1998) are emitted each year; an amount that can not be ignored. The amount of PNMC that is included in $1 \mathrm{~kg}$ of DEP is $28 \mathrm{mg}$ (Taneda et al. 2004a). The environmental concentrations of PNMC are not well known since research into the isolation of the compounds found in DEP has only just begun. In addition, PNMC is a known degradation product of the insecticide fenitrothion (Bhushan et al. 2000), which is used widely in many countries and is accumulating in air, soils and water (Nishioka et al. 1988, Nishioka \& Lewtas 1992). According to the data submitted by the pollutant release and transfer registers (PRTR), the amount of fenitrothion emitted into the environment in 2002 in Japan was approximately 1300 tons, and roughly half of this is degraded into PNMC (Hayatsu et al. 2000). Asman et al. (2005) also reported that the amount of PNMC contained in the rainwater in Roskilde, Denmark was as high as $2483 \mathrm{ng} / \mathrm{l}$. These findings clearly indicate that PNMC exists in large amounts in the environment from diesel exhaust, fenitrothion used on farms, and in rainwater. It is difficult to directly interpret the present results of the effects of PNMC on wildlife since the doses do not relate to the environmental concentration. However, as seen in the results from this research, it is certain that PNMC has toxic effects on the reproductive system, and therefore the possibility that the large amounts of PNMC in the environment will have serious effects on wildlife and human beings can not be ignored.

In conclusion, the present study clearly shows that PNMC impairs reproductive function in male Japanese quail through toxic effects on the hypothalamus, pituitary and testis.

\section{Acknowledgements}

We thank Dr G D Niswender, Animal Reproduction and Biotechnology Laboratory, Colorado State University (Fort Collins, CO, USA) for providing antiserum to testosterone (GDN 250); Dr John A Proudman, USDA-ARS, Biotechnology and Germplasm Laboratory (Beltsville, MD, USA) for LH radioimmunoassay materials; and the Biosignal Research Center, Institute for Molecular and Cellular Regulation, Gunma, Japan for providing antiserum against $\mathrm{LH}$. 


\section{Funding}

This study was supported in part by a Grant-in-Aid for Scientific Research (Basic research C-17510052 and B-18310044, and the 21st Century Center-ofExcellence-program, E-1) from the Ministry of Education, Culture, Sports, Science and Technology of Japan; and a Sasakawa Scientific Research Grant from The Japan Science Society (16-278). The authors declare that there is no conflict of interest that would prejudice the impartiality of this scientific work.

\section{References}

Ashby J, Lefevre PA, Tinwell H, Odum J \& Owens W 2004 Testosterone-stimulated weanlings as an alternative to castrated male rats in the Hershberger anti-androgen assay. Regulatory Toxicology and Pharmacology 39 229-238.

Asman WA, Jorgensen A, Bossi R, Vejrup KV, Mogensen BB \& Glasius M 2005 Wet deposition of pesticides and nitrophenols at two sites in Denmark: measurements and contributions from regional sources. Chemosphere 59 1023-1031.

Balthazart J \& Hendrick JC 1978 Steroidal control of plasma luteinizing hormone, comb growth and sexual behaviour in male chicks. Journal of Endocrinology 77 149-150.

Balthazart J, Schumacher M \& Malacarne G 1984 Relative potencies of testosterone and 5 alpha-dihydrotestosterone on crowing and cloacal gland growth in the Japanese quail (Coturnix coturnix japonica). Journal of Endocrinology 100 19-23.

Bhushan B, Samanta SK, Chauhan A, Chakraborti AK \& Jain RK 2000 Chemotaxis and biodegradation of 3-methyl-4-nitrophenol by Ralstonia sp. SJ98. Biochemical and Biophysical Research Communications 275 129-133.

EPA (US Environmental Protection Agency) 1996 Avian Reproduction Test. OPPTS 850-2300 'Public Draft' Ecological Effects Test Guidelines. EPA 712-C-96-141. Washington, DC, USA: United States Environmental Protection Agency.

Furuta C, Suzuki AK, Taneda S, Kamata K, Hayashi H, Mori Y, Li C, Watanabe G \& Taya K 2004 Estrogenic activities of nitrophenols in diesel exhaust particles. Biology of Reproduction 70 1527-1533.

Furuta C, Li C, Taneda S, Suzuki AK, Kamata K, Watanabe G \& Taya K 2005 Immunohistological study for estrogenic activities of nitrophenols in diesel exhaust particles. Endocrine 27 33-36.

Furuya M, Sasaki F, Hassanin AM, Kuwahara S \& Tsukamoto Y 2003 Effects of bisphenol-A on the growth of comb and testes of male chicken. Canadian Journal of Veterinary Research 67 68-71.

Gay VL \& Kerlan JT 1978 Serum LH and FSH following passive immunization against circulating testosterone in the intact male rat and in orchidectomized rats bearing subcutaneous silastic implants of testosterone. Archives of Andrology 1 257-266.

Hattori M \& Wakabayashi K 1979 Isoelectric focusing and gel filtration studies on the heterogeneity of avian pituitary luteinizing hormone. General and Comparative Endocrinology 39 215-221.

Hayatsu M, Hirano M \& Tokuda S 2000 Involvement of two plasmids in fenitrothion degradation by Burkholderia sp. strain NF100. Applied and Environmental Microbiology 66 1737-1740.

Ichinose T, Yajima Y, Nagashima M, Takenoshita S, Nagamachi Y \& Sagai M 1997 Lung carcinogenesis and formation of 8-hydroxy-deoxyguanosine in mice by diesel exhaust particles. Carcinogenesis 18 185-192.

Japan Environmental Agency 1998 A research report on the total amount of emissions and automobile exhaust. Chapter on source unit NOX according to object automobile in the usual transit (In Japanese), pp 200-203.
Kaku A, Chang C, Tamura T, Okamoto T \& Yoshimura Y 1993 Immunolocalization of androgen receptor in the cloacal gland of male Japanese quail (Coturnix coturnix japonica). Japanese Poultry Science 30 413-418.

Klinefelter GR, Hall PF \& Ewing LL 1987 Effect of luteinizing hormone deprivation in situ on steroidogenesis of rat Leydig cells purified by a multistep procedure. Biology of Reproduction 36 769-783.

Krishnan KA, Proudman JA \& Bahr JM 1994 Purification and partial characterization of isoforms of luteinizing hormone from the chicken pituitary gland. Comparative Biochemistry and Physiology, Biochemistry and Molecular Biology 108 253-264.

Kwan S, Hess RA, Bunick D, Nitta H, Janulis L, Osawa Y \& Bahr JM 1995 Rooster testicular germ cells and epididymal sperm contain P450 aromarase. Biology of Reproduction 53 1259-1264.

Lillie FR 1952 Development of the Chick, edn 3. Hamilton, NY, USA: Henry Holt.

Lin M \& Jones RC 1992 Renewal and proliferation of spermatogonia during spermatogenesis in the Japanese quail, Coturnix coturnix japonica. Cell and Tissue Research 267 591-601.

McClellan RO 1987 Health effects of exposure to diesel exhaust particles. Annual Review of Pharmacology and Toxicology 27 279-300.

Miyabara Y, Ichinose T, Takano H \& Sagai M 1998 Diesel exhaust inhalation enhances airway hyperresponsiveness in mice. International Archives of Allergy and Immunology 116 124-131.

Mori Y, Kamata K, Toda N, Hayashi H, Seki K, Taneda S, Yoshino S, Sakushima A, Sakata M \& Suzuki AK 2003 Isolation of nitrophenols from diesel exhaust particles (DEP) as vasodilatation compounds. Biological and Pharmaceutical Bulletin 26 394-395.

Muranaka M, Suzuki S, Koizumi K, Takafuji S, Miyamoto T, Ikemori R \& Tokiwa H 1986 Adjuvant activity of diesel-exhaust particulates for the production of IgE antibody in mice. Journal of Allergy and Clinical Immunology 77 616-623.

Nishioka MG \& Lewtas J 1992 Quantification of nitro- and hydroxylated nitro-aromatic/polycyclic aromatic hydrocarbons in selected ambient air daytime winter samples. Atmospheric Environment 26A 2077-2087.

Nishioka MG, Howard CC \& Contos DA 1988 Detection of hydroxylated nitro aromatic and hydroxylated nitro polycyclic aromatic compounds in an ambient air particulate extract using bioassay-directed fractionation. Environmental Science and Technology 22 908-915.

OECD (Organization for Economic Cooperation and Development) 1993. OECD Guidelines for the Testing of Chemicals. Section $2-$ Effect on Biotic Systems: Test Guideline 206: Avian Reproduction Test (adopted April 1984). Paris, France: OCD.

Ottinger MA \& Brinkley HJ 1979a Testosterone and sex related physical characteristics during the maturation of the male Japanese quail (Coturnix coturnix japonica). Biology of Reproduction 20 905-909.

Ottinger MA \& Brinkley HJ $1979 b$ The ontogeny of crowing and copulatory behaviour in Japanese quail. Behavioural Processes 4 43-51.

Perrin FM, Stacey S, Burgess AM \& Mittwoch U 1995 A quantitative investigation of gonadal feminization by diethylstilboestrol of genetically male embryos of the quail Coturnix coturnix japonica. Journal of Reproduction and Fertility 103 223-226.

Purohit VD, Basrur PK \& Bhatnagar MK 1977 Histochemical localization of 3 beta-hydroxysteroid dehydrogenase in the testes of chicken-pheasant hybrids. Histochemical Journal 9 293-299.

Rissman EF, Ascenzi M, Johnson P \& Adkins-Regan E 1984 Effect of embryonic treatment with oestradiol benzoate on reproductive morphology, ovulation and oviposition and plasma LH concentrations in female quail (Coturnix coturnix japonica). Journal of Reproduction and Fertility 71 411-417.

Rosenstrauch A, Weil S, Degen AA \& Friedlander M 1998 Leydig cell functional structure and plasma androgen level during the decline in fertility in aging roosters. General and Comparative Endocrinology 109 251-258. 
Sagai M, Saito H, Ichinose T, Kodama M \& Mori Y 1993 Biological effects of diesel exhaust particles. I. In vitro production of superoxide and in vivo toxicity in mouse. Free Radical Biology and Medicine 14 37-47.

Senger PL 1999 Endocrinology of the male and spermatogenesis. In The Pathways to Pregnancy and Parturition, edn 1, pp 168-186. Senger PL, Moscow, Russia: The Mack Printing Group Science Press.

Takafuji S, Suzuki S, Koizumi K, Tadokoro K, Miyamoto T, Ikemori R \& Muranaka M 1987 Diesel-exhaust particulates inoculated by the intranasal route have an adjuvant activity for $\operatorname{IgE}$ production in mice. Journal of Allergy and Clinical Immunology 79 639-645.

Taneda S, Kamata K, Hayashi H, Tada N, Seki K, Sakushima A, Yoshino S, Yamaki K, Sakata M, Mori Y et al. 2004a Investigation of vasodilatory substances in diesel exhaust particles (DEP): isolation and identification of nitrophenol derivatives. Journal of Health Science 50 133-141.

Taneda S, Mori Y, Kamata K, Hayashi H, Furuta C, Li C, Seki K, Sakushima A, Yoshino S, Yamaki K et al. $2004 b$ Estrogenic and anti-androgenic activity of nitrophenols in diesel exhaust particles (DEP). Biological and Pharmaceutical Bulletin 27 835-837.

Taya K, Watanabe G \& Sasamoto S 1985 Radioimmunoassay for progesterone, testosterone, and estradiol-17 $\beta$ using

${ }^{125}$ I-iodohistamine radioligands. Japanese Journal of Animal Reproduction 31 186-197.
Tsukue N, Toda N, Tsubone H, Sagai M, Jin WZ, Watanabe G, Taya K, Birumachi J \& Suzuki AK 2001 Diesel exhaust (DE) affects the regulation of testicular function in male Fischer 344 rats. Journal of Toxicology and Environmental Health A 63 115-126.

Tsukue N, Tsubone H \& Suzuki AK 2002 Diesel exhaust affects the abnormal delivery in pregnant mice and the growth of their young Inhalation Toxicology 14 635-651.

Watanabe N \& Oonuki Y 1999 Inhalation of diesel engine exhaust affects spermatogenesis in growing male rats. Environmental Health Perspectives 107 539-544.

Yamada T, Kunimatsu T, Sako H, Yabushita S, Sukata T, Okuno Y \& Matsuo M 2000 Comparative evaluation of a 5-day Hershberger assay utilizing mature male rats and a pubertal male assay for detection of flutamide's antiandrogenic activity. Toxicological Sciences $53289-296$.

Yoshida S, Sagai M, Oshio S, Umeda T, Ihara T, Sugamata M, Sugawara I \& Takeda K 1999 Exposure to diesel exhaust affects the male reproductive system of mice. International Journal of Andrology 22 307-315.

Received in final form 17 February 2006

Accepted 22 February 2006

Made available online as an Accepted Preprint 24 February 2006 